\title{
Impact of VSC Converter Topology on Fault Characteristics in HVDC Transmission Systems
}

\author{
Dimitrios Tzelepis $^{\dagger}$, Sul Ademi ${ }^{\dagger}$, Dimitrios Vozikis ${ }^{\dagger}$, Adam Dyśko ${ }^{\dagger}$, Sankara Subramanian*, Hengxu Ha* \\ ${ }^{\dagger}$ University of Strathclyde, Glasgow, $U K$, \\ dimitrios.tzelepis@strath.ac.uk,sul.ademi@strath.ac.uk,dimitrios.vozikis@strath.ac.uka.dysko@strath.ac.uk \\ ${ }^{*}$ General Electric Grid Solutions, Stafford, UK, \\ sankara.subramanian@alstom.com,hengxu.ha@alstom.com
}

Keywords-High voltage direct current (HVDC), DC faultanalysis, VSC converter topology, modular multi-level converter (MMC), IEC-61869, IEC-61850:9-2

\begin{abstract}
This work presents the outcome of a comprehensive study that assesses the transient behaviour of two high voltage direct current (HVDC) networks with similar structures but using different converter topologies, termed two-level and half-bridge (HB) modular multilevel converter (MMC). To quantify the impact of converter topology on DC current characteristics a detailed comparative study is undertaken in which the responses of the two HVDC network transients during dc side faults are evaluated. The behaviour of the HVDC systems during a permanent pole-to-pole and poleto-ground faults are analysed considering a range of fault resistances, fault positions along the line, and operational conditions as a prerequisite. Fast Fourier Transform (FFT) has been conducted analysing $d i / d t$ for both converter architecture and fault types taking into consideration sampling frequency of $96 \mathrm{kHz}$ in compliance with IEC-61869 and IEC61850:9-2 for DC-side voltages and currents.
\end{abstract}

\section{Introduction}

In recent years, voltage source converter high-voltage directcurrent (VSC-HVDC) transmission systems have become competitive compared to systems that employ thyristor current source converters in terms of power handling capability, $\mathrm{dc}$ operating voltage and technology maturity $[1,2]$. Such improvements have been realised employing two-level converters with series connected insulated gate bipolar transistors (IGBTs) and modular multilevel converters (MMCs), as shown in Figures $1 \mathrm{a}$ and $1 \mathrm{~b}$ respectively $[3,4]$. These advancements are expected to be the technology of choice for efficient grid integration. One of the main barriers for the deployment of HVDC system is the clearance of DCside faults. Various studies have been conducted to analyse the system behaviour during DC cable faults, and a number of methods for fault location and isolation have been reported [5-7]. Fault vulnerability and high-speed protection are the major issues that constrain the development of VSC-based DC networks [8], particularly in high-power scenarios and with more than two terminals. Isolation of a faulted DC line has been proposed by utilisation of DC circuit breakers [913]. However, the development of such breakers for highvoltage applications has presented a challenge for years, since unlike in AC systems, there is no natural current zero within DC systems, therefore such a breaker would have to force the current to zero and dissipate the energy stored in the system inductance [14-16]. The VSC-based transmission systems are robust to the fault conditions on AC-side, however, the most critical challenge for VSC-HVDC systems lies in its response to DC-cable faults.

Unfortunately, the two-level VSCs are defenceless against DC-side faults since their freewheeling diodes function as an uncontrolled rectifier bridge and feed the DC fault $[6,7,17$, 18], even if the semiconductor devices are turned off. Some efforts to characterise pole-to-pole and pole-to-ground faults based on VSC systems have been carried out in [5, 6, 18] and some characteristics have been established. However, further in-depth analysis into the converters behaviour is needed to improve understanding of system operation under fault conditions, and thus aid the development of effective DC protection methods.

Therefore, this paper provides detailed analysis on the behaviour of a VSC-HVDC converter during the DC poleto-pole and pole-to-ground faults for two-level and halfbridge submodule (HB-SM) systems in order to evaluate and understand the DC fault characteristics and their transient behaviours. The paper is organised as follows. In Section 2, a theoretical analysis of DC-side faults is carried out, both for classical two-level VSCs and HB-MMCs. Section 3 presents detailed simulation results and their analysis. Finally, Section 4 , concludes the main findings.

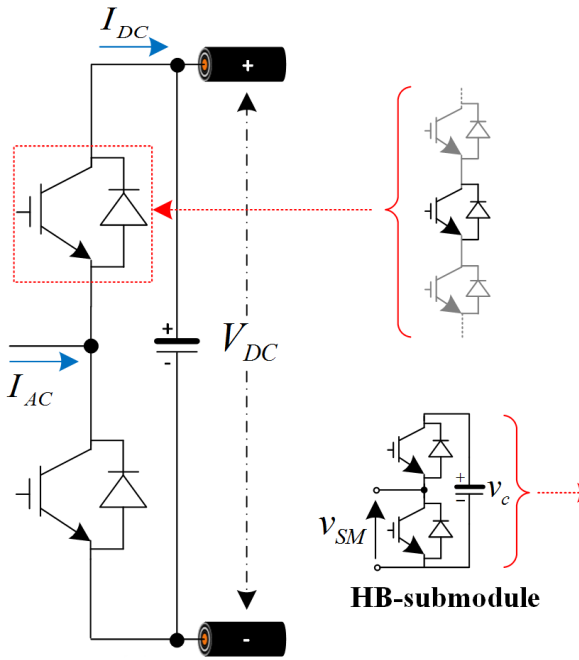

(a) Two-level converter

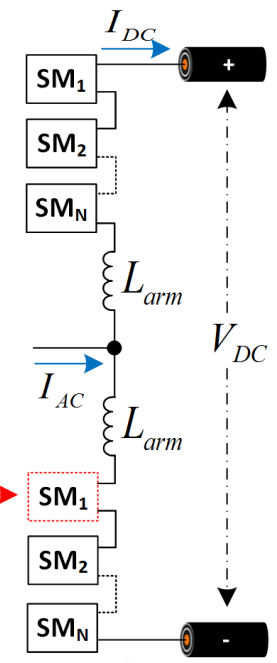

(b) $\mathrm{HB}-\mathrm{MMC}$
Figure 1: HVDC converter phase units. 


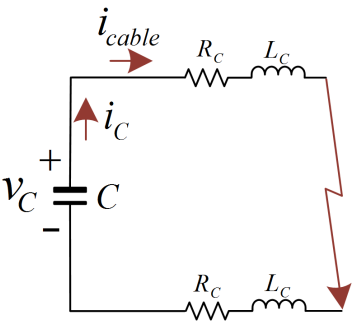

(a) Capacitor discharge

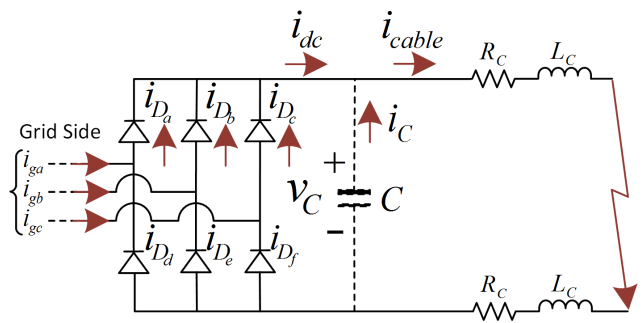

(b) Diode freewheeling

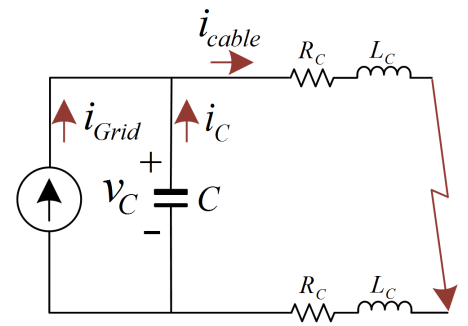

(c) Grid current feeding

Figure 2: Two-level VSC cable pole-to-pole fault.

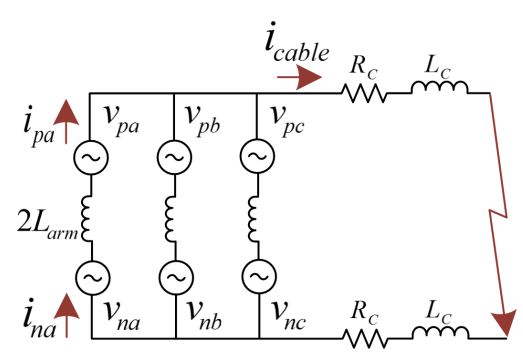

(a) IGBT Transition

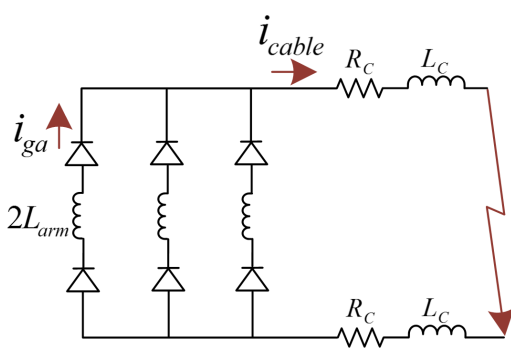

(b) Diode freewheeling

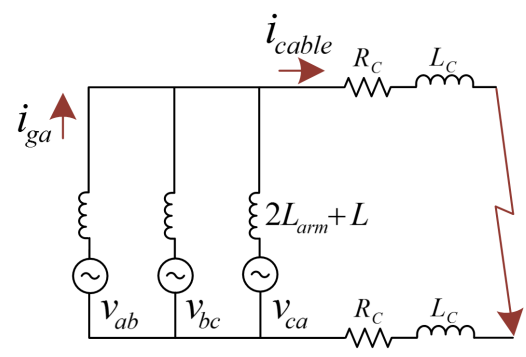

(c) Grid current feeding

Figure 3: HB-MMC cable pole-to-pole fault.

\section{HVDC Faults}

\subsection{Pole-to-pole faults}

Such faults occur as a result of direct contact or insulation breakdown between positive and negative conductors of a DC cable. Pole-to-Pole faults are not common but can be severe to the system. A pole-to-pole fault fed from a two-level VSC can be divided into the following three stages (also illustrated in Figure 2) [6, 18].

- Stage 1. Capacitor discharge: As Figure 2a depicts, the DC-link capacitor starts discharging rapidly, consequently the DC voltage collapse occurs. The natural fault current response is characterised by a high peak and fast rate of change.

- Stage 2. Diode freewheeling: This stage is initiated when the DC fault commutates to the converter freewheeling as shown in Figure $2 \mathrm{~b}$. This is the most hazardous period as the circulating fault current can destroy the anti-parallel diodes.

- Stage 3. Grid-side current feeding: During this stage the IGBTs are blocked and the converter behaves as an uncontrolled rectifier, injecting current into the DC side fault. The grid current contribution into fault $\left(i_{\text {Grid }}\right)$ is the sum of the positive three-phase fault currents.

In an MMC a pole-to-pole fault can be also analysed in three stages. However, due to the lack of DC-link capacitor the initial response is different to the aforementioned two-level converter. The equivalent circuits representing such converter arrangement during the fault are shown in Figure 3.

- Stage 1. IGBT Transition: This is a transient occurring after the fault inception and before the IGBTs are turned off. The equivalent circuit during this transition is illustrated in Figure $3 \mathrm{a}$.
- Stage 2. Diode freewheeling: This stage is initiated once the IGBTs are blocked. From this point the current will start passing through the diodes as indicated in Figure 3b. Concerning the arm currents at this stage, one arm current will rise while the other will be reduced to zero. The arm and cable inductance will determine the time duration of this stage.

- Stage 3. Grid-side current feeding: The fault current reaches its steady state. The equivalent circuit is shown in Figure 3c. This stage is identical to the one analysed for the two-level converter.

\subsection{Pole-to-ground faults}

Pole-to-pole faults are more common but at the same time they are less harmful to the system, compared to the poleto-pole faults. In practice such faults are triggered when the insulation of the cable breaks and the live conductor touches the ground (directly or through other conducting path). During this type of faults the earthing arrangement of the system plays a significant role, as different current loops can be formed. Various earthing configurations can be achieved, and there is no specific standard, especially for MTDC netowrks [17]. Furthermore, the ground fault resistance cannot be ignored as its value can vary significantly, hence it is integrated into the short-circuit analysis.

Assuming a $\Delta / Y_{g}$ transformer (with the $\mathrm{Y}$ winding on the converter side) and mid-point earthed DC-link capacitors, a pole-to ground fault for a two-level converter can be analysed using the following stages:

- Stage 1. Capacitor discharge: The DC-link voltage will be disturbed, however it will not collapse towards zero. Consequently no free-wheeling diode conduction is present. Even though the DC-link voltage is sustained, the faulty-pole voltage collapses to zero, while the healthy pole voltage rises toward 2 p.u. [18]. Such rise can introduce concerns regarding the voltage insulation of individual conductors. 


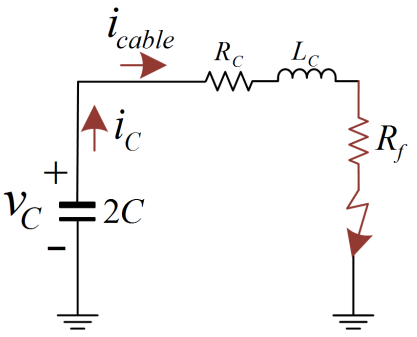

(a) Two-level: Capacitor discharge

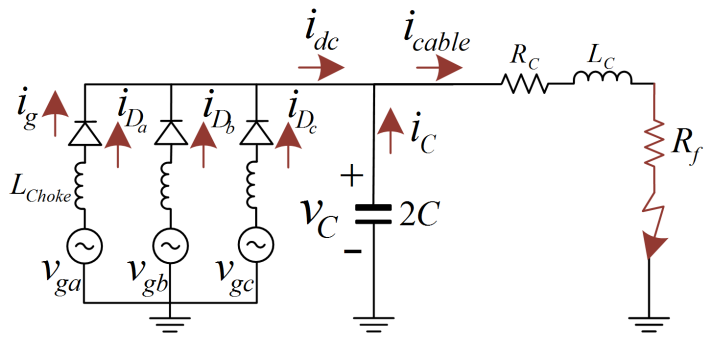

(b) Two-level: Grid current feeding

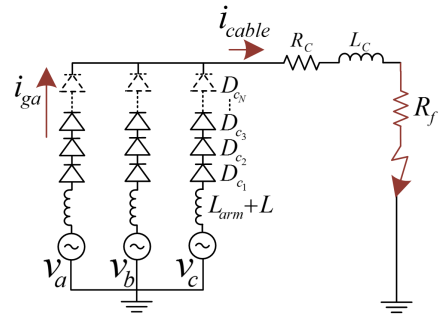

(c) HB-MMC: Grid current feeding

Figure 4: Two-level and MMC cable pole-to-ground fault.

- Stage 2. Grid-side current feeding: During this stage, even though the IGBTs are rapidly blocked, the ACside fault current keeps feeding the fault through the converter free-wheeling diodes. This is illustrated in Figure 4b.

For MMC configuration with the same earthing arrangement of the transformer, the analysis for a pole-to-ground fault is much simpler. In fact, as a DC-link capacitor is absent, the pole-to-ground fault has only the steady state stage as illustrated in Figure $4 \mathrm{c}$, which is initiated after the blocking of the IGBTs. Again, in this case the faulty-pole voltage collapses to zero, while the healthy pole voltage rises toward 2 p.u, similarly to the two-level converter.

\section{Simulation-based Fault Analysis}

This section includes comparative analysis of the HVDC network transients during dc faults. The simulation results are generated utilising Matlab-Simulink ${ }^{\circledR}$ environment. The DC cable model is based on the Bergeron's travelling wave method (also used in the Electromagnetic Transient Program (EMTP) [19]). An automatic simulation routine was developed to iteratively change the fault position and resistance in order to capture the natural response of the system under a variety of fault conditions. Network parameters used for the AC grid (including transformers) and DC cable model are presented in Table 1, while the converter parameters (for two-Level and MMC) can be seen in Table 2. The fault location and ground fault resistance values used in simulation (for pole-to-pole and pole-to-ground) are included in Table 3. Distance to fault values mentioned within the paper and indicated on the result figures take as reference point the rectifier station.

The captured DC current and voltage measurements have been re-sampled at $96 \mathrm{kHz}$, with conjunction of low pass filter been applied prior to re-sampling in order to avoid any aliasing problems in compliance with IEC-61869 and IEC61850:9-2. Taking into account the requirements of a fast DC protection system, the rate of change of DC current $(d i / d t)$ and voltage $(d u / d t)$ have been calculated using $0.25 \mathrm{~ms}$ time window. All faults are triggered at $t=0.5 \mathrm{~s}$ and graphs are illustrated considering a $16 \mathrm{~ms}$ time window (including $2 \mathrm{~ms}$ pre-fault stage). Within the context of MTDC protection, semiconductor devices (in case of MMC) were not programmed to switch off during the faults. Hence natural response of the converter has been investigated, to ensure that during the faults external DC-line protection would isolate the fault, and the VSC station would remain connected to the DC grid. Based on the analysed results presented here the emphasis is put on the current characterisation. For VSCHVDC applications it is believed that the transient current components are more applicable as the DC capacitors form the fundamental boundaries of the DC transmission [20, 21]. However, in order to offer a better insight into the fault response, maximum values of $d u / d t$ are also included in Table 4 (but not shown in figures due to space limitations).

\begin{tabular}{||l||l||}
\hline \hline Parameter & Value \\
\hline \hline DC Line Resistance $\left[R_{D C}\right]$ & $15.0 \mathrm{~m} \Omega / \mathrm{km}$ \\
\hline DC Line Inductance $\left[L_{D C}\right]$ & $0.96 \mathrm{mH} / \mathrm{km}$ \\
\hline DC Line Capacitance $\left[C_{D C}\right]$ & $0.012 \mu \mathrm{F} / \mathrm{km}$ \\
\hline DC Line Length & $300 \mathrm{~km}$ \\
\hline \hline AC Voltage (L-L, RMS) & $400 \mathrm{kV}$ \\
\hline AC Frequency & $50 \mathrm{~Hz}$ \\
\hline X/R Ratio of AC Network & 10 \\
\hline AC Short-Circuit Level & $2 \mathrm{GVA}$ \\
\hline Interfacing Transformer Voltages & $400 / 330 \mathrm{kV}$ \\
\hline \hline
\end{tabular}

Table 1: DC Cable and AC Network Parameters

\begin{tabular}{||l||c||c||}
\hline \hline Parameter & HB-MMC & Two-Level VSC \\
\hline \hline DC Voltage $\left[V_{d c}\right]$ & $\pm 320 \mathrm{kV}$ & $\pm 320 \mathrm{kV}$ \\
\hline DC-Link Capacitance $\left[C_{d c}\right]$ & - & $100 \mu \mathrm{F}$ \\
\hline IGBT $\left[R_{o n}\right]$ & $1 \mathrm{~m} \Omega$ & $1 \mathrm{~m} \Omega$ \\
\hline Arm Inductance $\left[L_{a r m}\right]$ & $2.3 \mathrm{mH}$ & - \\
\hline Sub-module Capacitance $\left[C_{S M}\right]$ & $50 \mu \mathrm{F}$ & - \\
\hline Choke Inductance $\left[L_{C h o k e}\right]$ & $50 \mathrm{mH}$ & $60 \mathrm{mH}$ \\
\hline \hline
\end{tabular}

Table 2: Converter Parameters

\begin{tabular}{||c||c||c||c||}
\hline \hline Case & Dist. $[\mathrm{km}]$ & Sub-case & $\mathbf{R}_{\mathrm{f}}[\Omega]$ \\
\hline \hline 1 & 25 & $\mathrm{a}$ & 25 \\
\hline 2 & 75 & $\mathrm{~b}$ & 50 \\
\hline 3 & 150 & $\mathrm{c}$ & 100 \\
\hline 4 & 200 & $\mathrm{~d}$ & 200 \\
\hline 5 & 299 & $\mathrm{e}$ & 300 \\
\hline \hline
\end{tabular}

Table 3: Fault location and ground fault resistance values

The results presented in Figures 5 to 8 which are obtained for pole-to-pole faults inject high initial currents into the cable. This is expected due to the specific structure of the MMC and lack of common DC link capacitors, thus the fault current produced by MMC is lower than the two-level. Even when the MMC's semiconductor devices are not turned off and sub-module capacitance is included in the fault loop, the fault current is still lower due to the fact that the overall capacitance is decreased as a result of series connection of the individual capacitors.

Is can be observed that distance to fault has a significant impact on the current characteristics. As expected, for close up faults the rise of current is faster and the current magnitude reaches higher levels due to lower overall fault loop impedance. Therefore, the converter and associated cable are 
more vulnerable. With longer distance to fault, the values of $\mathrm{R}$ and $\mathrm{L}$ included in the fault loop naturally increase. The higher values of $L$ increase the rise time (by limiting the rate of change of current), while higher values of $R$ reduce the current peak values. The reduction of rate of change can be observed both on voltages and currents in Table 4 . In case of pole-to-ground faults the fault resistance seems to have a predominant limiting effect on the fault current. However, higher fault resistance does not provide any increase of the rise time, as it does not include any additional inductance.

To better illustrate the impact of distance to fault and ground fault resistance, Table 4 includes maximum values reached for $d i / d t$ and $d u / d t$ for the two-level converter and HBMMC. It can be observed that fault position and resistance have a limiting effect on $d i / d t$ in all cases while $d u / d t$ does not behave in the same way. In particular, for pole-to-ground faults, the rate of change of voltage increases with distance to fault, and decreases with ground fault resistance.

In order to gain better understanding of such fault characteristics a Fast Fourier Transform (FFT) of $d i / d t$ has been carried out for both converter architectures and both types of faults. Figure 9a shows FFT analysis results for a pole-to-pole fault at $25 \mathrm{~km}$. It can be seen that the majority of frequency content is located towards the lower side of the spectrum. The most striking feature of the graph is that the MMC frequency content is significantly higher than the one imposed by the two-level converter. In particular, there are distinguishable frequency components located roughly between 0.5 and 2.5 $\mathrm{kHz}$. However, it can be noticed that for pole-to-pole fault the two-level converter imposes higher amplitudes in the frequency range below $1 \mathrm{kHz}$. The FFT analysis depicted in Figure 9b illustrates the frequency spectrum of a poleto-ground fault current. In this case the MMC frequency content is observed to be higher than the two-level VSC. This is noticeable through the entire frequency spectrum. The detailed FFT based analysis (which also takes into account signal re-sampling at $96 \mathrm{kHz}$ ) provided the following observations :

- The frequency spectrum of interest for both types of faults lies in the range between 0 and $3 \mathrm{kHz}$.

- In case of pole-to-pole faults the two-level converter introduces higher frequency components within the range below $1 \mathrm{kHz}$.

- While under the same fault condition as above the HB-MMC imposes higher amplitudes above $1 \mathrm{kHz}$, while on the contrary the two-level VSC amplitudes are practically zero beyond that frequency range.

- In case of pole-to-ground faults, the FFT analysis has indicated that HB-MMC has higher frequency components throughout the entirety of the frequency spectrum when closely compared to the two-level VSC spectrum.

\section{Conclusions}

Integration of high-capacity offshore renewable energy onto transmission networks is stimulating the applications of VSC-HVDC transmission networks. In this paper, pole-topole and pole-to-ground fault analysis of the conventional VSC-based and MMC dc systems have been performed. Definitions of the stages of the fault response are described which assist in identifying the most serious stage of a fault. Based on the fault current waveform analysis (including signal sampling frequency of $96 \mathrm{kHz}$ ), the following observations can be made:

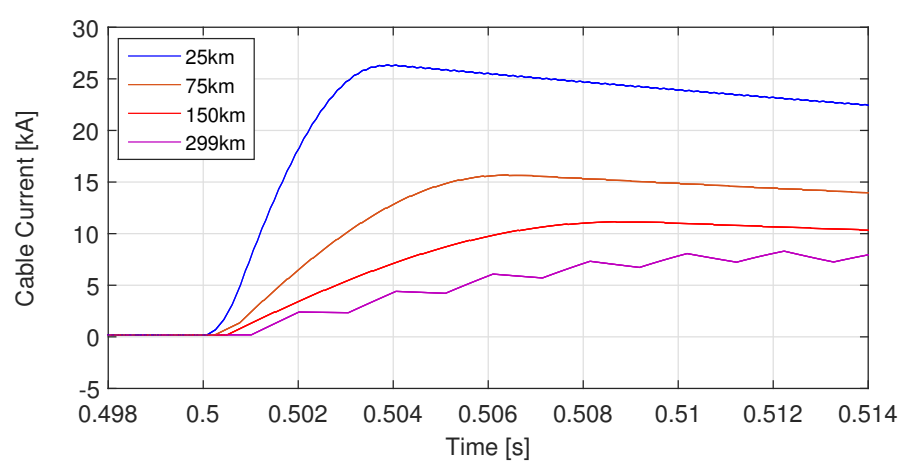

(a) Cable current

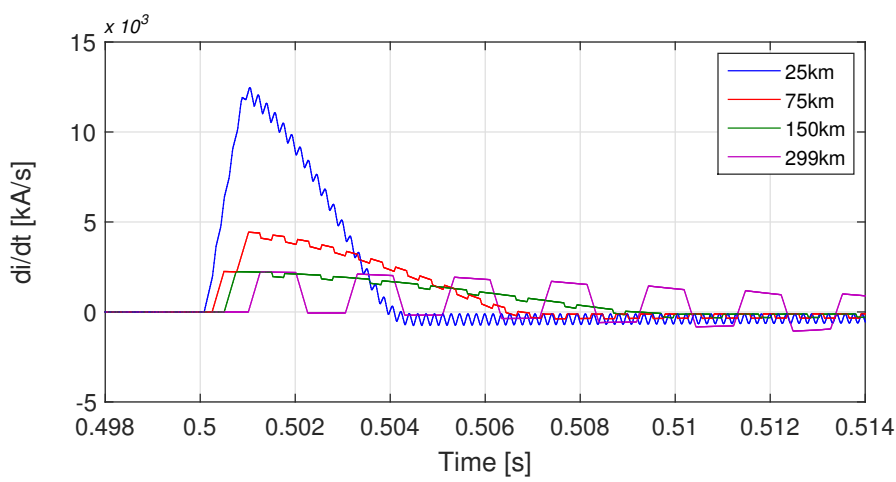

(b) Rate of change of cable current

Figure 5: Two-level VSC respone for pole-to-pole fault at different locations.

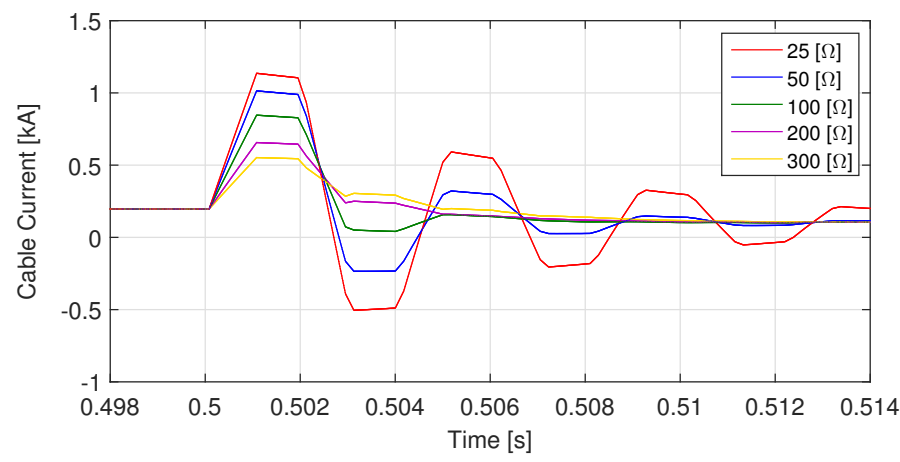

(a) Cable current

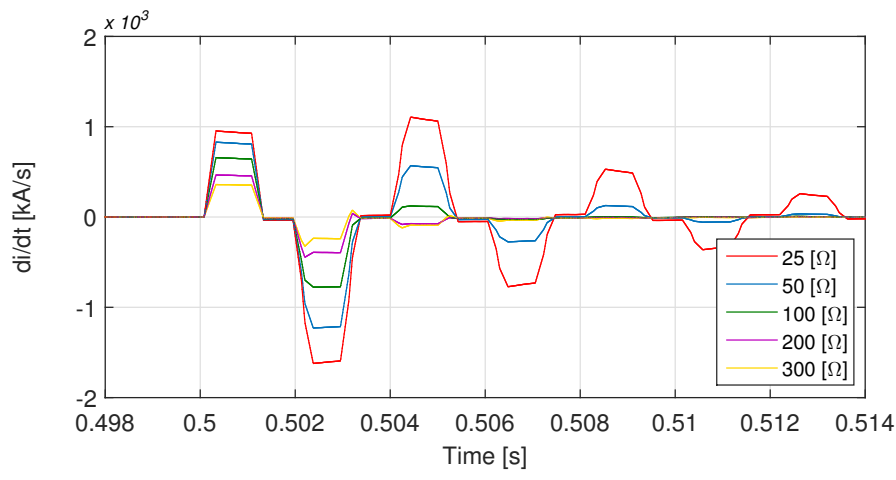

(b) Rate of change of cable current

Figure 6: Two-level VSC respone for pole-to-ground fault at $25 \mathrm{~km}$ and different ground fault resistances.

- The short fault current rise time and its high magnitude make the converter and associated cable vulnerable, especially during close up pole-to-pole faults. 


\begin{tabular}{|c|c|c|c|c|c|c|c|c|c|c|c|c|}
\hline $\mathbf{R}_{\mathbf{f}}[\Omega] \rightarrow$ & \multicolumn{2}{|c|}{25} & \multicolumn{2}{|c|}{50} & \multicolumn{2}{|c|}{100} & \multicolumn{2}{|c|}{200} & \multicolumn{2}{|c|}{300} & \multicolumn{2}{|c|}{0 (pole-to-pole) } \\
\hline Dist. $[\mathrm{km}] \downarrow$ & $d i / d t$ & $d u / d t$ & $d i / d t$ & $d u / d t$ & $d i / d t$ & $d u / d t$ & $d i / d t$ & $d u / d t$ & $d i / d t$ & $d u / d t$ & $d i / d t$ & $d u / d t$ \\
\hline \multicolumn{13}{|c|}{ Two-level } \\
\hline 25 & 1621.2 & 273848.4 & 1222.8 & 238643.1 & 776.2 & 189832.5 & 464.9 & 154507.1 & 359.4 & 138813.2 & 12101.9 & 127401.9 \\
\hline 75 & 1608.5 & 275077.4 & 1217.0 & 239450.1 & 766.3 & 190288.3 & 467.4 & 154148.0 & 360.6 & 138557.4 & 4430.8 & 74970.6 \\
\hline 150 & 965.0 & 276617.2 & 837.4 & 240664.1 & 662.3 & 191018.2 & 467.0 & 135241.7 & 360 & 104688.3 & 2238.0 & 51890.9 \\
\hline 200 & 948.2 & 542142.0 & 824.5 & 471739.0 & 653.8 & 374481.3 & 462.4 & 265155 & 357.7 & 205243.5 & 2232.1 & 45224.6 \\
\hline 299 & 48.5 & 537171.0 & 42.2 & 467489.6 & 33.6 & 371185.4 & 23.8 & 262880.5 & 18.5 & 203566.6 & 2222.4 & 37801.0 \\
\hline \multicolumn{13}{|c|}{ HB-MMC } \\
\hline 25 & 1395.9 & 391720.7 & 1090.4 & 380493.6 & 733.0 & 347617.5 & 467.7 & 287281.0 & 361.5 & 241537.0 & 8907.7 & 175464.0 \\
\hline 75 & 1302.8 & 391765.0 & 1085.7 & 381001 & 730.3 & 347782.5 & 465.2 & 286281.0 & 360.7 & 240558.7 & 4360.4 & 193730.7 \\
\hline 150 & 952.6 & 539165.1 & 828.6 & 469176.9 & 657.4 & 372480.9 & 465.3 & 293176.7 & 360.1 & 251154.5 & 2230.3 & 142741.4 \\
\hline 200 & 935.5 & 538910.0 & 801.5 & 469180.3 & 656.1 & 372360.9 & 459.8 & 297876.2 & 347.6 & 262157.8 & 2228.7 & 129007.7 \\
\hline 299 & 98.4 & 538250.2 & 85.6 & 468600.7 & 68.0 & 372261.6 & 48.4 & 308900.4 & 37.6 & 276947.6 & 2238.0 & 111406.0 \\
\hline
\end{tabular}

Table 4: Maximum values of current and voltage derivatives in $[\mathrm{kA} / \mathrm{s}]$ and $[\mathrm{kV} / \mathrm{s}]$ respectively.

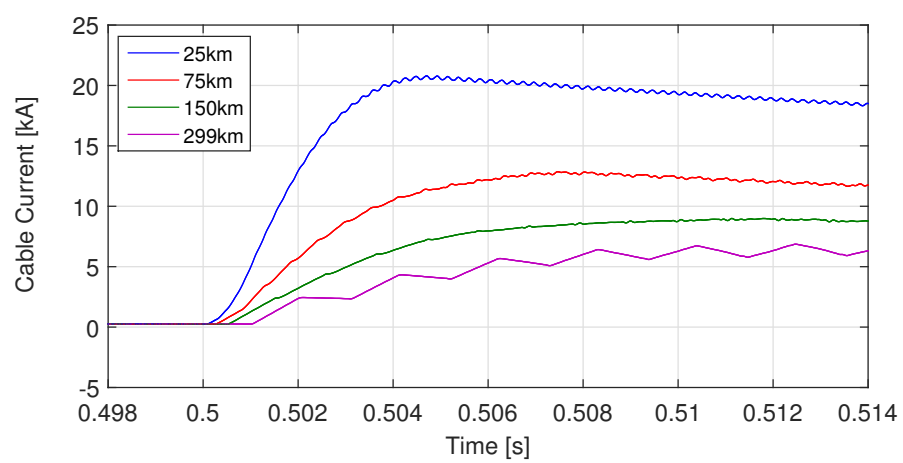

(a) Cable current

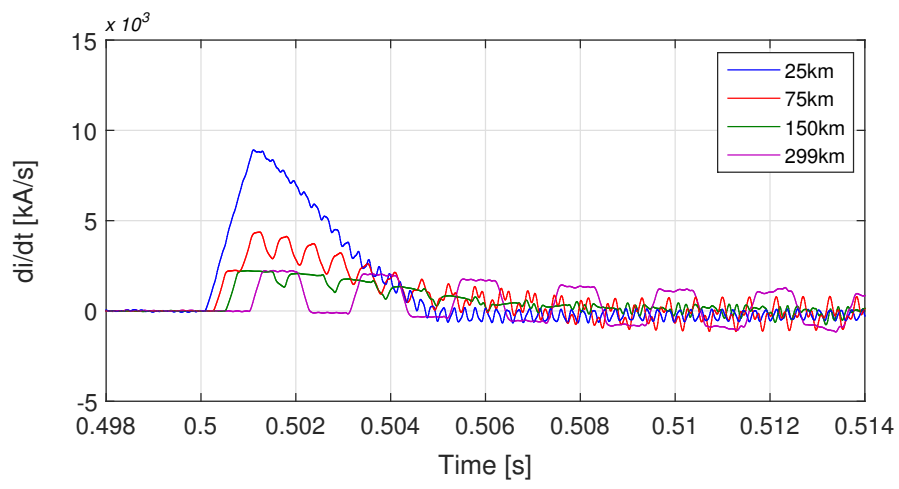

(b) Rate of change of cable current

Figure 7: HB-MMC response for pole-to-pole fault at different fault locations.

- The conventional VSC-based generates the larger DC fault current levels, which is primarily due to the large DC-link capacitor.

- Fault current natural responses are simulated and analysed using the calculated values of $d i / d t$ and $d u / d t$ as well as their frequency spectrum obtained using FFT. The results show that MMC-based faults have higher frequency components compared to the conventional VSC-based system throughout the entire frequency spectrum.

- Results have shown that both distance to fault and fault resistance have a limiting effect on $d i / d t$.

- In the case of pole-to-ground faults, the rate of change of voltage increases with distance to fault, and decreases with higher vales of ground fault resistance.

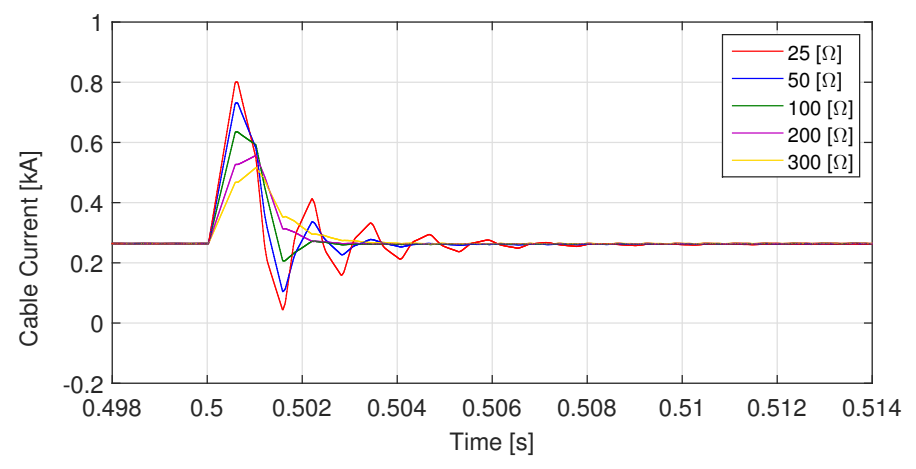

(a) Cable current

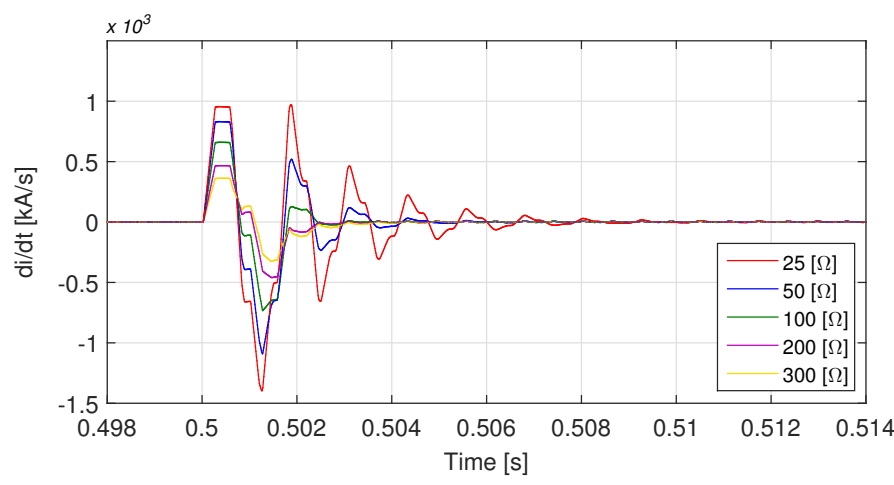

(b) Rate of change of cable current

Figure 8: HB-MMC respone for pole-to-ground fault at 25 $\mathrm{km}$ and different ground fault resistances.

The analysis presented in this paper form a basis towards the multi-terminal protection scheme design. It has been determined that fast and selective DC line fault detection is required to make use of initial transient fault signatures. In the next step the characterisation of differences between the internal and external faults will be investigated. On-going and future work is targeting the development and demonstration of such a system.

\section{Acknowledgements}

The authors would like to thank General Electric Grid Solutions, Stafford, UK, for their technical and financial support. Authors are grateful for being given the possibility to carry out this work. 


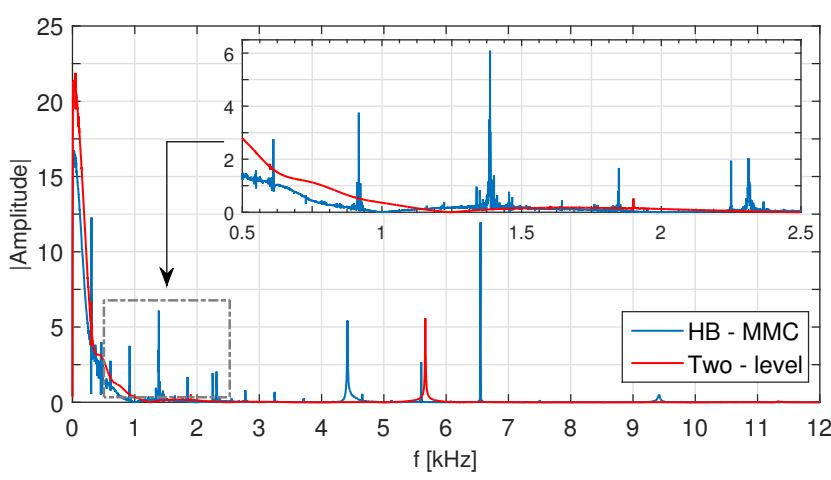

(a) Pole-to-pole fault at $25 \mathrm{~km}$

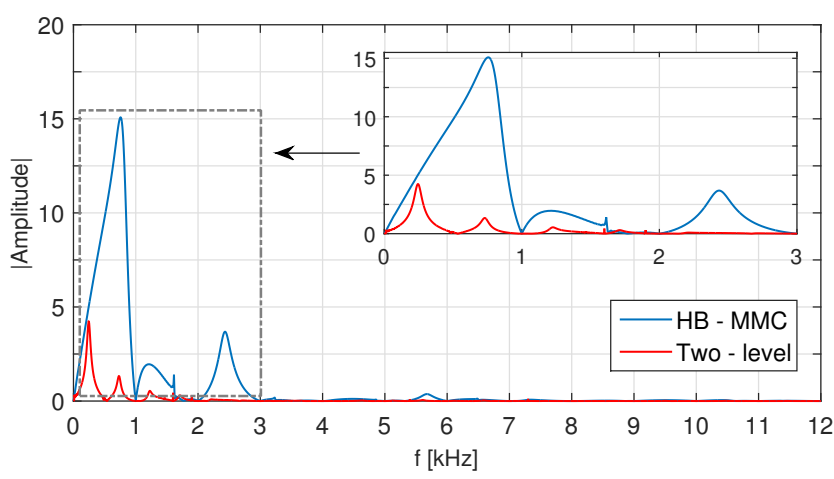

(b) Pole-to-ground fault at $25 \mathrm{~km}$ and $25 \Omega$ ground fault resistance

Figure 9: FFT analysis of $d i / d t$ for two-level and HB-MMC converters.

\section{References}

[1] D. V. Hertem and M. Ghandhari., "Multi-terminal VSCHVDC for the european supergrid: Obstacles," Renewable and Sustainable Energy Reviews, vol. 14, no. 9, pp. 3156 - 3163, 2010.

[2] D. Jovcic, D. Van Hertem, K. Linden, J.-P. Taisne, and W. Grieshaber, "Feasibility of dc transmission networks," in Innovative Smart Grid Technologies, 2nd IEEE PES International Conference and Exhibition on, Dec 2011.

[3] S. Cole and R. Belmans, "Transmission of bulk power," Industrial Electronics Magazine, IEEE, vol. 3, no. 3, pp. 19-24, 2009.

[4] L. Zhang, L. Harnefors, and H.-P. Nee, "Modeling and control of VSC-HVDC links connected to island systems," Power Systems, IEEE Transactions on, vol. 26, no. 2, pp. 783-793, 2011.

[5] L. Tang and B.-T. Ooi, "Locating and isolating DC faults in multi-terminal DC systems," Power Delivery, IEEE Transactions on, vol. 22, no. 3, pp. 1877-1884, July 2007.

[6] J. Yang, J. Fletcher, and J. O'Reilly, "Short-circuit and ground fault analyses and location in VSC-based DC network cables," Industrial Electronics, IEEE Tran. on, vol. 59, no. 10, pp. 3827-3837, Oct 2012.

[7] J. Rafferty, L. Xu, and J. Morrow, "Analysis of voltage source converter-based high-voltage direct current under DC line-to-earth fault," Power Electronics, IET, vol. 8, no. 3, pp. 428-438, 2015.

[8] H. Ha and S. Subramanian, "Implementing the protection and control of future dc grids," Alstom Grid Technology Centre, Innovation and Technology Department, Jan 2015.
[9] C. Greiner, T. Langeland, J. Solvik, and O. Rui, "Availability evaluation of multi-terminal dc networks with dc circuit breakers," in PowerTech, IEEE Trondheim, 2011, pp. 1-8.

[10] C. Franck, "HVDC circuit breakers: A review identifying future research needs," Power Delivery, IEEE Transactions on, vol. 26, no. 2, pp. 998-1007, April 2011.

[11] M. Callavik, A. Blomberg, J. Hafner, and B. Jacobson, "The hybrid HVDC breaker," in ABB Grid Systems, November 2012.

[12] M. Hajian, D. Jovcic, and B. Wu, "Evaluation of semiconductor based methods for fault isolation on high voltage dc grids," Smart Grid, IEEE Transactions on, vol. 4, no. 2, pp. 1171-1179, June 2013.

[13] K. Sano and M. Takasaki, "A surgeless solid-state dc circuit breaker for voltage-source-converter-based hvdc systems," Industry Applications, IEEE Transactions on, vol. 50, no. 4, pp. 2690-2699, July 2014.

[14] C. Barker and R. Whitehouse, "An alternative approach to HVDC grid protection," in AC and DC Power Transmission, 10th IET International Conference on, 2012, pp. 1-6.

[15] J. Hafner and B. Jacobson, "Proactive hybrid HVDC breakers - A key innovation for reliable HVDC grids," in Cigre Symp, Sep 2011, pp. 358-361.

[16] B. Xiang, Z. Liu, Y. Geng, and S. Yanabu, "DC circuit breaker using superconductor for current limiting," Applied Superconductivity, IEEE Transactions on, vol. 25, no. 2, pp. 1-7, April 2015.

[17] J. Rafferty, L. Xu, and D. Morrow, "DC fault analysis of VSC based multi-terminal HVDC systems," in AC and DC Power Transmission, 10th IET International Conference on, Dec 2012, pp. 1-6.

[18] S. Ademi, D. Tzelepis, A. Dysko, S. Subramanian, and H. Ha, "Fault current characterisation in VSC-based HVDC systems," in Development in Power System Protection, IET Conference on, March 2016.

[19] H. Dommel, "Digital computer solution of electromagnetic transients in single-and multiphase networks," Power Apparatus and Systems, IEEE Transactions on, vol. PAS-88, no. 4, pp. 388-399, April 1969.

[20] G. Song, X. Cai, D. Li, S. Gao, and J. Suonan, "A novel pilot protection principle for vsc-hvdc cable lines based on fault component current," International Journal of Electrical Power \& Energy Systems, vol. 53, pp. 426433, December 2013.

[21] A. Adamczyk, C. Barker, and H. Ha, "Fault detection and branch identification for hvdc grids," in Developments in Power System Protection, 12th IET International Conference on, March 2014, pp. 1-6. 